\title{
Presentación del dossier. \\ Marx y la crítica ecosocialista del capital. Implicaciones conceptuales y políticas desde América Latina
}

Presentation of the Dossier.

Marx and the ecosocialist critique of capital. Conceptual and political implications from Latin America

Durante décadas se desestimaron los aportes de Karl Marx a la reflexión y el activismo ambientales. Se acusaba a este autor de haber mantenido un optimismo en cuanto a que las fuerzas productivas podrían vencer eventualmente cualquier límite natural, y de haber considerado a la naturaleza desde un punto de vista estrictamente antropocéntrico y utilitario.

Por ello, una primera generación de ecosocialistas intentó "hacer verde" al marxismo mediante la crítica de las supuestas insuficiencias ecológicas de Marx (y del socialismo histórico) y mediante la inserción de algunos elementos marxistas en una Teoría Verde predominantemente neo-malthusiana. Este grupo, que abarca, entre otros, los enfoques de Ted Benton, Ariel Salleh y Joan Martínez-Alier, consideraba que era necesario complementar a Marx con otras teorías sobre la ecología para articular las luchas ambientales y las socialistas.

En una segunda etapa, la ampliación del corpus de los escritos de Marx y su lectura sistemática desde la temática ambiental, sin embargo, han demostrado la centralidad de la relación entre sociedad y naturaleza en la crítica marxiana del capitalismo, y su reconocimiento de los límites que el medio ambiente le impone a las sociedades. Más aún, autores como Paul Burkett, John B. Foster y Kohei Saito han argumentado que Marx fue crítico de los "costos sociales" que el capital exterioriza hacia la población y la naturaleza, generando contradicciones ecológicas que eventualmente tienen graves efectos sociales.

Los alcances de esta revisión de la producción de Marx no son solamente de carácter teórico - al mostrar la unidad de teoría social y ambiental - sino político, al plantear la necesidad de convergencia entre la lucha de las clases trabajadoras y la defensa del medio ambiente. La tercera etapa del ecosocialismo, por ello, ya aplica normalmente conceptos marxianos como los de metabolismo social, fractura metabólica y base naturalmaterial del valor de uso normalmente para comprender problemas tales como el metabolismo del carbono, la 
justicia ambiental de género, la ecología marina, la dependencia de fertilizantes de nitrógeno, y el imperialismo ecológico, entre otros. Resaltan aquí las investigaciones de Naomi Klein y Andreas Malm sobre combustibles fósiles (Foster \& Burkett, 2017, pp. 1-11).

Este dossier explora algunas de las implicaciones para América Latina de este renovado ecosocialismo, tanto en lo conceptual como en lo político. Así, el artículo de Luna-Nemecio emprende la crítica de las limitaciones de la economía convencional respecto al tema ecológico, y muestra, en contraste, cómo el diálogo con las categorías básicas de la crítica marxiana permite hacer visibles las contradicciones entre el capital y la sostenibilidad de la naturaleza. En este sentido, el concepto de subsunción real del consumo, desarrollado por Jorge Veraza a partir de El capital, permite explicar la devastación ambiental. Lo característico de la crítica del capital, nos dice, está en la discusión de las condiciones de posibilidad del capitalismo, las cuales no son problematizadas desde la economía convencional, aunque pretenda dar cuenta de los problemas ecológicos mediante una economía ambiental.

A su vez, Escalera Briceño y Palafox Muñoz abordan el problema del turismo y la extracción de arena en el Caribe mexicano desde el concepto de frontera mercantil de Jason Moore. Analizan con ello otro caso del capital en busca de naturaleza barata para explotar y sacar ganancias, externalizando los costos hacia las poblaciones locales y al ecosistema. Esta aplicación de conceptos de la tradición de la crítica de la economía política demuestra que, más allá de los actores económicos individuales, el propio sistema económico es el que produce la violencia estructural manifiesta en la desposesión social y la devastación de la naturaleza.

Las relaciones entre capitalismo, ecología y género son el tema central del artículo de Badilla Fallas, "La vuelta a Marx: el problema de la fundamentación del materialismo encarnado". Esta elaboración se da mediante el diálogo con el materialismo encarnado de Ariel Salleh. La valoración crítica de Badilla indica varias limitaciones en el enfoque de Salleh (en particular su falta de historicidad), pero también aportes necesarios desde el enfoque de género para pensar estrategias frente a la expoliación de la naturaleza. Tales aportes, argumenta el artículo, pueden potenciarse al enmarcar su ecofeminismo en el materialismo ecológico para comprender mejor los mecanismos comunes de opresión de género y naturaleza en el capitalismo.

Herrera Rodríguez enfoca su investigación en las implicaciones del capital en las relaciones entre Estado y naturaleza, a partir de las cuales esboza varios elementos conceptuales para una ecología política con base en la crítica marxiana de la fractura metabólica. A lo largo de su exposición, Herrera argumenta que la teoría de Marx preconfigura el concepto de biopolítica desarrollado mucho tiempo después por Michel Foucault, y que esta aproximación es fundamental para pensar la relación socio-metabólica del capital.

Finalmente, el artículo de Campos Madrigal aborda la apropiación de Bolívar Echeverría del concepto marxiano de valor de uso, y explora sus implicaciones respecto a los temas ecológicos. Particularmente, resalta el lugar del concepto de transnaturalización en Echeverría como una tensión de lo humano con sus condiciones naturales: aunque este concepto tiene elementos en común con la fractura metabólica, apunta hacia posibilidades ausentes en ella.

De este modo, los artículos reunidos en este dossier dan fe de las posibilidades explicativas y la actualidad del aparato teórico fundado por Karl Marx frente al socio-metabolismo del capital. A 
partir de allí se pueden vislumbrar estrategias y relaciones entre actores a nivel regional y global que ayuden a contrarrestar la lógica destructiva del modo de producción hoy imperante en el mundo.

$* * *$

Queremos expresar nuestro profundo pesar por el fallecimiento durante el proceso editorial de este dossier del Dr. Alejandro Palafox Muñoz. Estudioso y crítico de los efectos de la mercancialización de los espacios naturales, nos quedan hoy sus intervenciones sobre el turismo en México, y especialmente sobre el Caribe de ese país. Su pérdida se sentirá en la academia y en el activismo ecosocialista latinoamericano. Que descanse en poder.

\section{REFERENCIAS}

Angus, I. (2016) Facing the Anthropocene: Fossil Capitalism and the Crisis of the Earth System. Monthly Review Press.

Bonneuil, C., \& Fressoz, J.-B. (2017). The Shock of the Anthropocene. The Earth, History and Us. Verso.

Burkett, P. (2014) Marx and Nature: A Red and Green Perspective. Monthly Review Press.

Flores Mondragón, G. J. (2018). Karl Marx: Naturaleza y crítica de la economía política. Religación. Revista de Ciencias Sociales y Humanidades, 3(11), 77-89. https://revista.religacion.com/index.php/religacion/ article/view/166

Foster, J.B. (2000) Marx's Ecology: Materialism and Nature. Monthly Review Press.

Foster, J.B. , \& Burkett, P. (2017) Marx and the Earth: An Anti-Critique. Haymarket.

Foster, J.B., Clark, B., \& York, R. (2011) The Ecological Rift: Capitalism's War on the Earth. Monthly Review Press. Klein, N. (2015) Esto lo cambia todo. El capitalismo contra el clima. Paidós.

Malm, A. (2016) Fossil Capital. The Rise of Steam Power and the Roots of Global Warming. Verso.

Moore, J. W. (2015) Capitalism in the Web of Life. Ecology and the Accumulation of Capital. Verso.

Moore, J. W. (ed.) (2016) Anthropocene or Capitalocene? Nature, History, and the Crisis of Capitalism. PM Press.

Saito, K. (2017) Karl Marx's Ecosocialism: Capital, Nature, and the Unfinished Critique of Political Economy. Monthly Review Press.

Smith, N. (2008) Uneven Development. Nature, Capital and the Production of Space. The University of Georgia Press.

Tagliavini, D., y Sabbatella I. (2012) Marxismo ecológico: elementos fundamentales para la crítica de la economía-política-ecológica. Marxismo crítico: https://cutt.ly/rEdTXvd

Tijoux, M. E. (2016). El sociometabolismo del Capital y la depredación de la Vida. Debates sobre el extractivismo. Actuel Marx / Intervenciones, 20

\section{Editor Invitado}

George García Quesada. Profesor Catedrático de Filosofía. PhD, Kingston University London. Líneas de investigación: Teoría social, historia social, estética política, filosofía de la historia y de la historiografía. 